\title{
CONF-960/06--7
}

\section{NEUTRON DIFFRACTION MEASUREMENTS AND MODELING OF RESIDUAL STRAINS IN METAL MATRIX COMPOSITES}

\author{
A. Saigal and G.G. Leisk \\ Department of Mechanical Engineering \\ Tufts University \\ Medford, MA 02155 \\ C.R. Hubbard, S.T. Misture and X.L. Wang \\ High Temperature Materials Laboratory \\ Metals and Ceramics Division \\ Oak Ridge National Laboratory \\ Oak Ridge, TN 37831-6064
}

\begin{abstract}
Neutron diffraction measurements at room temperature are used to characterize the residual strains in tungsten fiber-reinforced copper matrix, tungsten fiber-reinforced Kanthal matrix, and diamond particulate-reinforced copper matrix composites. Results of finite element modeling are compared with the neutron diffraction data. In tungsten/Kanthal composites, the fibers are in compression, the matrix is in tension, and the thermal residual strains are a strong function of the volume fraction of fibers. In copper matrix composites, the matrix is in tension and the stresses are independent of the volume fraction of tungsten fibers or diamond particles and the assumed stress free temperature because of the low yield strength of the matrix phase.
\end{abstract}

\section{Introduction}

Tungsten fiber-reinforced copper composite systems provide high thermal conductivity and good creep/fatigue resistance, and as a consequence are considered for possible use in high temperature, space propulsion environments [1]. FeAl and FeCrAl alloys, such as Kanthal, have been shown to exhibit outstanding high-temperature oxidationicorrosion resistance and therefore have great potential for use as corrosionresistant cladding in a variety of high-temperature applications [2,3]. In addition, FeAl alloys and tungsten fiber-reinforced Kanthal metal matrix composites have been developed with improved mechanical behavior and weldability for possible applications in space structures [4]. However, thermal residual stresses are developed as a result of the mismatch of the coefficients of thermal expansion between those of the tungsten fibers 


\section{DISCLAIMER}

Portions of this document may be illegible in electronic image products. Images are produced from the best available original document. 
and the copper or Kanthal matrix during post-fabrication cooldown. These stresses may exceed the yield strength of the matrix, alter the initial yield surfaces and subsequent hardening response, and develop cracks in the matrix, thereby deteriorating the aggregate mechanical properties of the composites. To develop composites with reliable and enhanced properties, it is necessary to understand the nature and the magnitude of these residual strains and stresses. High-resolution neutron powder diffraction was used in this study to investigate the residual strains and stresses at room temperature in W/Copper and W/Kanthal composites containing different volume fractions of tungsten fibers. In addition, neutron diffraction was used to characterize the effect of volume fraction of diamond particles and $\mathrm{SiC}$ coating thickness on the residual strains in the particles and the matrix in diamond/copper composites, which are being developed for applications requiring high thermal conductivity.

\section{Background}

Theoretical and finite element models (FEM) have been used extensively to predict the residual stresses in particulate- and fiber-reinforced composites [5]. However, to determine parameters in the models and to verify them, it is desirable to experimentally measure the residual stresses in composite samples. X-ray and neutron diffraction are powerful, nondestructive techniques for characterizing residual stresses in crystalline materials [6-9]. When a material is subjected to a homogeneous strain field, the angular position of a diffraction peak will shift to lower or higher 2-theta values, depending on whether the strain is tensile or compressive, respectively. If the material is subjected to an inhomogeneous strain field, then in addition to a possible shift in the peak position, the diffraction peak profile might also be broadened. From the experimentally determined strains, the residual stresses can be deduced using appropriate models. Because neutrons have a penetration power several orders of magnitude higher than $X$-rays in most engineering materials, neutron diffraction is the preferred method for the measurement of bulk residual micro strains and stresses.

\section{Experimental Details}

Tungsten/copper composites containing 9 and $36 \mathrm{vol} . \%$ fibers and tungsten/Kanthal composites containing $10,20,30$, and 70 vol.\% fibers were fabricated at NASA Lewis Research Center using the liquid infiltration and arc-spray processes, respectively. The fibers were GE 218 tungsten fibers $200 \mu \mathrm{m}$ in diameter. The copper matrix consists of oxygen-free, high conductivity (OFHC) copper ( $99.95 \mathrm{w} / \mathrm{O} \mathrm{Cu}$ ). The 9 and $36 \mathrm{vol} . \% \mathrm{~W} / \mathrm{Cu}$ composite specimens were about $3 \times 12 \mathrm{~mm}$ and $6 \times 12 \mathrm{~mm}$ in cross-section, respectively. The specimens for diffraction measurements were about $10 \mathrm{~mm}$ long and cut from $200 \mathrm{~mm}$ long bars. The Kanthal matrix is of the following composition by weight percent: $73.2 \% \mathrm{Fe}, 21 \% \mathrm{Cr}, 5.8 \% \mathrm{Al}$ and $0.04 \% \mathrm{C}[10]$. The tungsten-Kanthal tapes with unidirectional fibers were hot pressed at $1065^{\circ} \mathrm{C}$ for $1 \mathrm{~h}$ before being cooled to room temperature. The final as-fabricated bars were approximately $25 \mathrm{~mm}$ wide, $2.5 \mathrm{~mm}$ thick and $200 \mathrm{~mm}$ long. Samples $25 \times 25 \mathrm{~mm}$ for the neutron diffraction measurements were then machined from the $200 \mathrm{~mm}$ bars using a diamond cut off wheel. In addition, a monolithic Kanthal bar containing no fibers was fabricated. The diamond particulate- 
reinforced copper samples were $10 \times 10 \times 10 \mathrm{~mm}$ in size and contained 20 or 50 vol.\% diamond particles ( $1.3 \mu \mathrm{m}$ diameter) coated with 20 or $70 \mathrm{~nm}$ thick SiC.

The neutron diffraction measurements were conducted using the $\mathrm{HB}-4$ high resolution powder diffractometer at the High Flux Isotope Reactor at Oak Ridge National Laboratory. Neutron powder diffraction patterns were collected at room temperature for two W/Cu composites, four W/Kanthal composites, three diamond/Cu composite samples, a monolithic Kanthal bar, OFHC copper, and pure tungsten fibers. The diffraction data were collected using $1.417 \AA$ neutrons from 40 to $135^{\circ} 2 \Theta$ at a step size of $0.05^{\circ}$. Each data set took from 6 to $12 \mathrm{~h}$ to collect. The samples were fully irradiated in the neutron beam, so the measurements represent a bulk average over the entire sample. In order to maximize the sensitivity of the measurements in fiber-reinforced composites to strains parallel to the fibers, the samples were placed in the beam so that the tungsten fibers were oriented at $57^{\circ}$ to the incident neutron beam and the tungsten (321), copper (331) and Kanthal (222) reflections around $114^{\circ} 2 \Theta$ were used to determine the strains (Figure 1). Diffraction peak locations and estimated standard deviations were determined by fitting Gaussian profiles to the observed data. The peak width at half maximum was about $0.5^{\circ} 2 \Theta$, and each profile was fitted to $\pm 0.01^{\circ}$ which yields a strain resolution of approximately $5 \times 10^{-5}$.

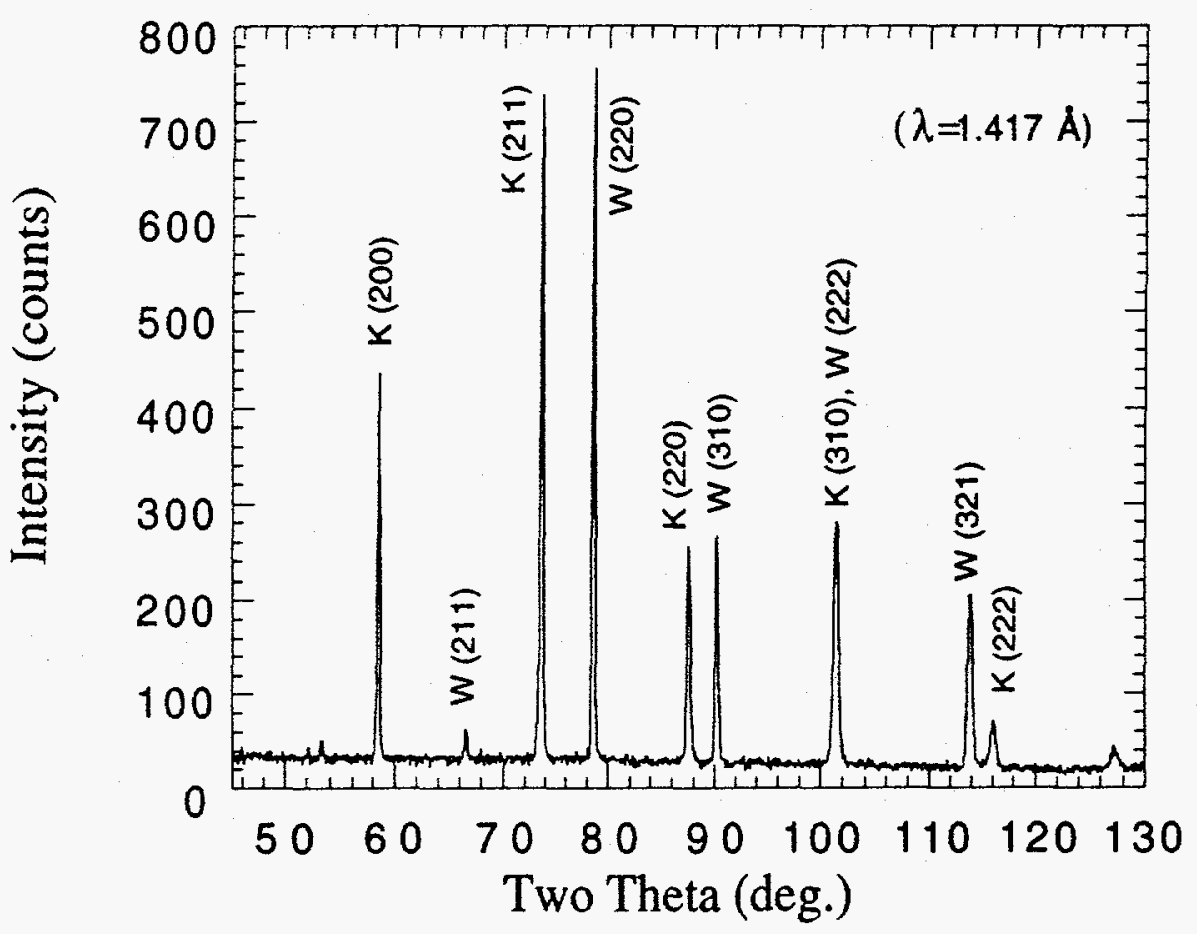

Figure 1 Neutron diffraction pattern of tungsten fiber $(W)$ - Kanthal matrix ( $K$ ) composite. 
The average lattice strain along a particular crystallographic direction, (hkl), is given by

$$
\varepsilon_{n k l}=\left(d \cdot d_{0}\right) / d_{0}
$$

where $d$ and $d_{o}$ are, respectively, the lattice spacing of the stressed and stress-free (reference) samples along (hkl). Once the average lattice strains are measured along the directions parallel (axial), $\varepsilon_{a}$, and perpendicular (transverse), $\varepsilon_{t}$, to the fibers, the residual stresses along these directions, $\sigma_{a}$ and $\sigma_{t}$, can be estimated using Hooke's law. Assuming transverse isotropy,

$$
\begin{aligned}
& \sigma_{\mathrm{a}}=E_{n k l}\left((1-v) \varepsilon_{\mathrm{a}}+2 v \varepsilon_{\mathrm{q}}\right) /(1+v)(1-2 v) \\
& \sigma_{\mathrm{l}}=E_{n k t}\left(v \varepsilon_{\mathrm{a}}+\varepsilon_{\mathrm{q}}\right) /(1+v)(1-2 v)
\end{aligned}
$$

where $E_{n k}$ is the diffraction Young's modulus and $v$ is the Poisson's ratio of the specific material considered.

\section{Finite Element Modeling}

The finite element model assumes that the W/Cu composites can be approximated by an infinite square array of cylindrical tungsten fibers in the copper matrix. In order to validate the model, the aggregate stress-strain curves of 28 and 67.4 vol.\% composites were generated using the commercially available finite element code ANSYS and were compared with the experimental, room temperature, tensile stress-strain curves in the direction parallel to the fiber axis and with data available in the literature for these composite systems $[1,11]$. As such, a one-quarter symmetry mesh was constructed that consisted of 168 eight-noded, solid, isoparametric, generalized plane strain elements. This micromechanical model represents a cross-section of the composite materials perpendicular to the fiber axis. The stress-free temperature was assumed to be $900^{\circ} \mathrm{C}$. The stress-free temperature of $900^{\circ} \mathrm{C}$ is $150-200^{\circ} \mathrm{C}$ below the liquid infiltration temperature and has been adopted by other researchers to avoid the significant viscoplastic material behavior present at high temperatures whereas $542^{\circ} \mathrm{C}$ represents the lowest limit for W/Cu composites system in the literature [14].

Elastic-plastic finite element analysis was performed. Temperature-dependent constituent material properties such as yield stress, Young's modulus and thermal expansion coefficients were included for both the tungsten fiber and the copper matrix $[12,13]$. The yield stress of the matrix corresponds to the annealed condition. The predicted and measured stress-strain curves are in excellent agreement for the two volume fractions of tungsten fibers (Fig. 2). In addition, it was found that the predicted stress-strain curves are quite similar, independent of the assumed stress-free temperature of 542 or $900^{\circ} \mathrm{C}$. This can be attributed to the low yield stress (35-40 MPa) of annealed OFHC copper. This model was then used to predict the residual strains and stresses in 9 and 36 vol.\% W/Cu composites. 


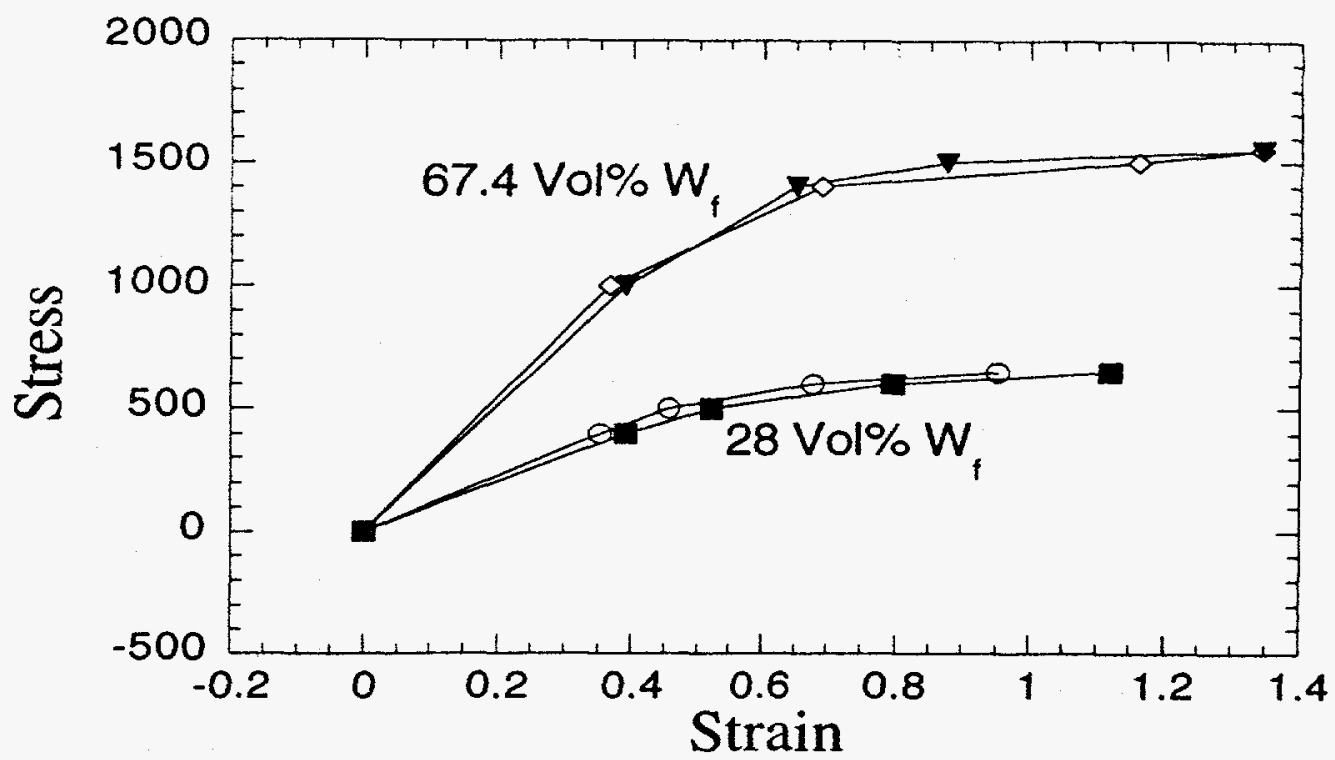

Figure 2. Predicted (solid symbols) and experimental (open symbols) stress-strain curves for 28 and 67.4 vol\% tungsten fiber/copper matrix composites.

\section{Results and Discussion}

\section{Tungsten/Copper Composites}

The measured axial strains in the fibers and the matrix in 9 and 36 vol.\% W/Cu composites are shown in Figure 3. The strain in the copper matrix is tensile and is between +0.0003 and +0.0004 and is essentially independent of the volume fraction of fibers in the composite. This is in agreement with the estimated value of +0.0003 from the finite element model. On the other hand, the measured axial residual strain in the $W$ fiber is compressive and decreases from -0.0017 to -0.0001 as the volume fraction of fibers is increased from 9 to $36 \%$. The estimated strain in the fibers (36 vol.\% composite) from FEM is -0.0002 , which is within the experimental error. However, the strain estimated by FEM in the fibers in the 9 vol.\% composite is only about -0.0011 . The discrepancy between measured and observed strains can be attributed to the variation in the local volume fraction of fibers. Using the ratio of the amplitude of the tungsten to copper peaks in Figure 4, the local volume fraction of the fibers in overall 9 vol.\% composite is estimated to be about $6 \%$. For 6 vol.\% fibers, the estimated strain in the fibers from finite element analysis is about -0.0016 , which is in agreement with the measured value. In addition, a volume fraction weighted force balance analysis supports the presence of 6 vol.\% fibers in the irradiated volume. 


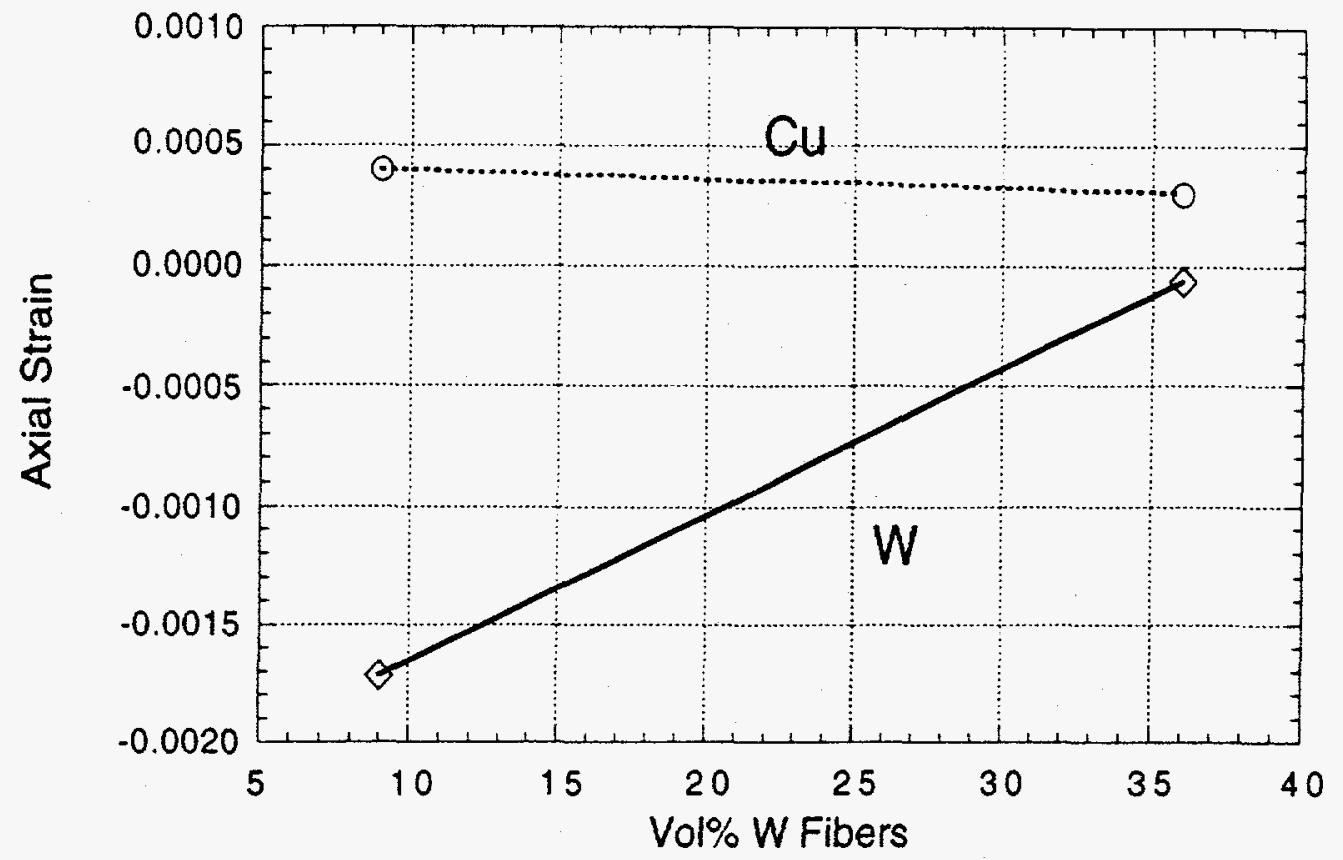

Figure 3. Axial strains in the fibers and the matrix in 9 and 36 vol.\% W/Cu composites.
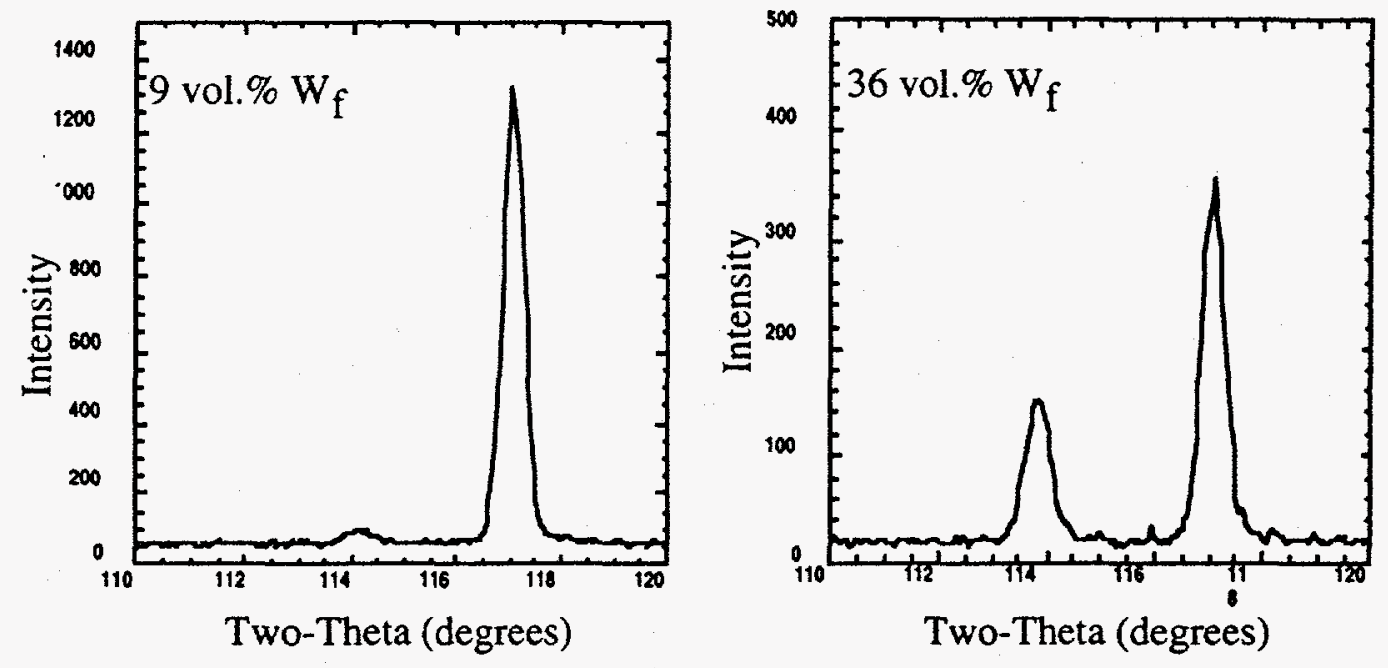

Figure 4. Neutron diffraction patterns for 9 and 36 vol.\% W/Cu composites. 


\section{Tungsten/Kanthal Composites}

The axial residual strain in the tungsten fibers and the Kanthal matrix ( Fig. 5a) were determined from the (321) line for tungsten and (222) line for Kanthal. The bulk axial strain in the tungsten fibers is compressive and varies from about -0.0020 to -0.0004 , whereas the bulk axial strain in the Kanthal matrix is tensile and increases from +0.0003 to +0.0027 as the amount of tungsten fibers in the composite increases from 10 to 70 vol.\%. Compressive strain in the tungsten fibers and tensile strain in Kanthal is expected as the coefficient of thermal expansion of Kanthal (about $9.5 \times 10^{-6} \mathrm{~K}^{-1}$ ) is greater than that of tungsten (about $4.5 \times 10^{-6} \mathrm{~K}^{-1}$ ).

The total axial strain measured in the fibers and the matrix is about 0.0030 for 20 to 70 vol.\% tungsten fiber-reinforced composites. Based on the total temperature drop of about $1000^{\circ} \mathrm{C}$ from the hot press temperature to room temperature, the total axial strain in the fibers and the matrix should be about 0.0050 . This is much greater than the measured value of 0.0030 , which indicates that the thermal residual stresses relax at high temperatures and that the stress-free temperature of the composites is much lower than the hot press temperature and should be around $650^{\circ} \mathrm{C}$. To verify this and model the residual stresses in W/Kanthal composites, it is necessary to conduct neutron diffraction measurements at elevated temperatures.

In addition to the above measurements, the composite samples were rotated by $90^{\circ}$ to measure the transverse strains perpendicular to the fibers. The measured strains perpendicular to the fibers in the 30 vol. \% composite are of the order of 0.0002 in the tungsten fibers and 0.0001 in the Kanthal matrix. Using $v$ and $E$, one can estimate the
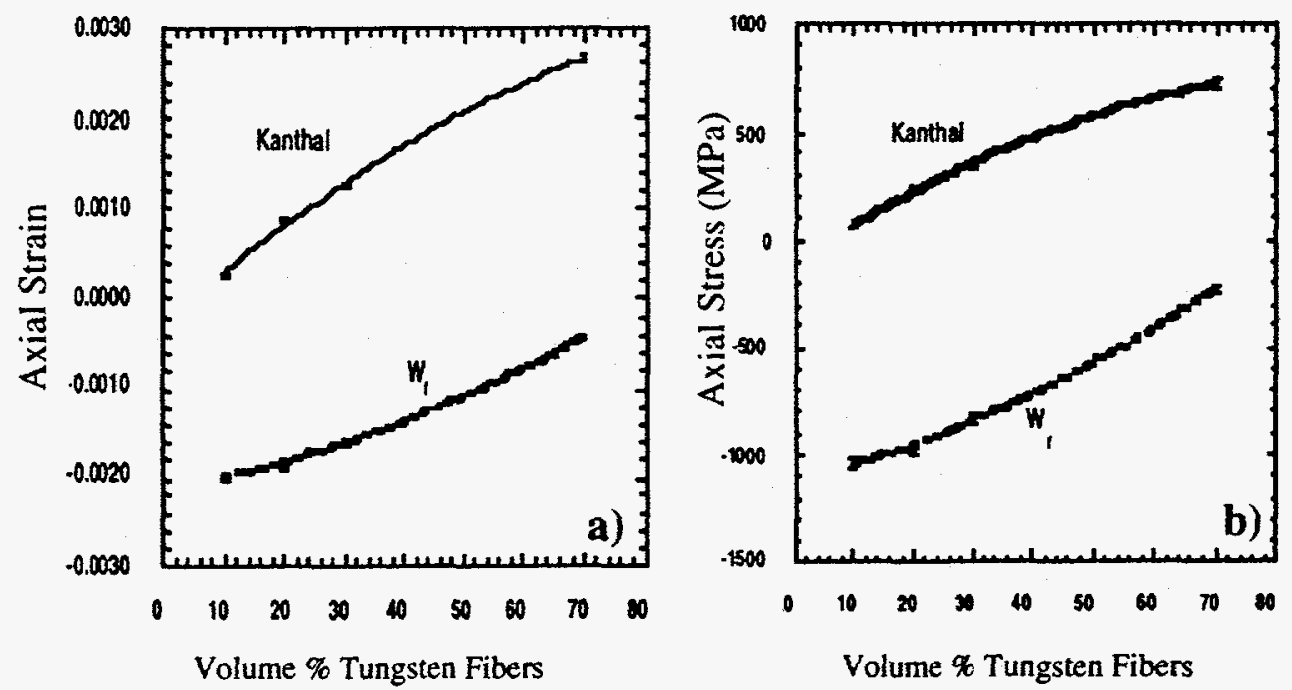

Figure 5. Axial residual strain (a) and axial residual stresses (b) as a function of the volume fraction of tungsten fibers $\left(W_{t}\right)$ in Kanthal matrix. 
residual stresses in the composites. Tungsten is exceptionally isotropic, so the (222) diffraction elastic constant of $410 \mathrm{GPa}$ was used, with $v=0.28$ [8]. The diffraction elastic constant for (211) iron of $203 \mathrm{GPa}$, which is representative of the bulk value, was used for Kanthal [15]. A value of 0.28 was used for $v$ for the Kanthal. The calculated residual stresses in the fibers and the matrix as a function of the volume fraction of fibers are shown in Fig. 5b. As the fiber content increases from 10 to $70 \mathrm{vol} \%$, the axial residual stress in the tungsten fibers decreases from -1035 to -230 MPa. On the other hand, the residual stress in the Kanthal matrix is tensile and increases from 60 to $720 \mathrm{MPa}$. For the $70 \mathrm{vol} . \%$ composite, this corresponds to an equivalent stress [11] of about $400 \mathrm{MPa}$ in the matrix which is less than the $530 \mathrm{MPa}$ yield stress of Kanthal.

\section{Diamond/Copper Composites}

Table I shows the measured $d$-spacing in diamond particulate-reinforced copper composites. The measured d-spacing (and corresponding residual strains) in the diamond particles as well as OFHC copper is found to remain constant, independent of the volume fraction of diamond particles. This can once again be attributed to the low yield stress of the OFHC copper matrix. However, it should be noted that within the limitations of the experimental measurements, the thickness of the SiC coating on the diamond particles seems to affect the d-spacing. As the SiC coating thickness increases from 20 to $70 \mathrm{~nm}$, the d-spacing decreases in both diamond and copper. As the coefficient of thermal expansion of copper is larger than that of diamond, this means that increasing the $\mathrm{SiC}$ coating thickness from 20 to $70 \mathrm{~nm}$ increases the compressive residual strain in diamond particles and decreases the tensile residual strain in the copper matrix. Using the ratio of the amplitude of the diamond to copper peaks verifies that the composites contain 20 and 50 vol.\% diamond particles.

Table I. Measured d-spacing in diamond/copper composites.

\begin{tabular}{|c|c|c|c|}
\hline Vol.\% Diamond & $\begin{array}{c}\text { SiC Coating } \\
\text { Thickness }(\mathrm{nm})\end{array}$ & $\begin{array}{c}\text { d-spacing of diamond } \\
(\mathrm{nm})\end{array}$ & $\begin{array}{c}\text { d-spacing of copper } \\
(\mathrm{nm})\end{array}$ \\
\hline 50 & 20 & 0.081795 & 0.080845 \\
\hline 20 & 70 & 0.081785 & 0.080830 \\
\hline 50 & 70 & 0.081785 & 0.080830 \\
\hline
\end{tabular}




\section{Conclusions}

High-resolution neutron powder diffraction has been used to measure the residual strains at room temperature in $\mathrm{W} / \mathrm{Cu}, \mathrm{W} / \mathrm{Kanthal}$ and diamond/copper composites. In W/Cu composites, the axial residual strain in the matrix is about +0.0003 . In W/Kanthal composites, the bulk axial strain in the tungsten fibers is compressive and varies from about -0.0020 to -0.0004 , whereas the bulk axial strain in the Kanthal matrix is tensile and increases from +0.0003 to +0.0027 as the amount of tungsten fibers in the composite increases from 10 to 70 vol.\%. Using elastic theory and the measured strains, this corresponds to compressive axial residual stress in tungsten fibers of -1035 to $-230 \mathrm{MPa}$ and tensile residual stress in the Kanthal matrix of 60 to $720 \mathrm{MPa}$. In addition, it appears that the thermal residual stresses relax at high temperatures and that the stress-free temperature of the composites should be around $650^{\circ} \mathrm{C}$. In diamond particulatereinforced copper composites, the d-spacing (and the corresponding residual strains) in the diamond particles as well as the OFHC copper is found to remain constant, independent of the volume fraction of diamond particles. Increasing the SiC coating thickness on diamond particles from 20 to $70 \mathrm{~nm}$ increases the compressive residual strain in diamond particles and decreases the tensile residual strain in the copper matrix.

\section{Acknowledgments}

This research was sponsored by the U.S. Department of Energy, Assistant Secretary for Energy Efficiency and Renewable Energy, Office of Transportation Technologies, as part of the High Temperature Materials Laboratory User Program, under contract DE-AC05-96OR22464, managed by Lockheed Martin Energy Research Corp. S.M. acknowledges the Oak Ridge National Laboratory Postdoctoral Research Associates Program administered jointly by the Oak Ridge National Laboratory and Oak Ridge Institute for Science and Education. G.L. acknowledges the NASA Graduate Student Researcher Program under contract NGT-50943. In addition, the authors would like to thank J.M. Pereira, NASA Lewis Research Center, for providing the composite samples, and A. Wereszczak and D. Braski for their valuable editorial comments.

\section{References}

1. D.L. McDanels, NASA Technical Paper 2924, 1989.

2. C.T. Liu, V.K. Sikka and C.G. McKamey, Alloy Development of FeAl Alloys for Structural Use in Corrosive Environments, Oak Ridge National Laboratory, ORNLTM-12199, February 1993.

3. J.E. Antill and K.A. Peakall, J. Iron Steel Inst., 205 1136, 1967.

4. P.J. Maziasz, G.M. Goodwin, C.T. Liu and S.A. David, Scripta Metall. Mat., 27 1835, 1992.

5. A. Saigal, D.S. Kupperman and S. Majumdar, Mater. Sci. Engrg., A150 [1] 59, 1992.

6. A.D. Krawitz and T.M. Holden, Mat. Res. Soc. Bull., 15 [11] 57, 1990.

7. X.L. Wang, C.R. Hubbard, K.B. Alexander, P.F. Becher, J.A. Femandez-Baca and S. Spooner, J. Amer. Ceram. Soc., 77[6], 1569, 1994. 
8. 1.C. Noyan and J.B. Cohen, Residual Stress Measurement by Diffraction and interpretation, Springer-Verlag, New York, 1987.

9. A. Saigal, D.S. Kupperman, J.P. Singh, D. Singh, Composites Engrg., 3 [11] 1075, 1993. for Metallic Composition Based on Matrix Testing: Application to Kanthal

ANPSiles, NASA TM 103172, June 1990.

12. ANSYS User's Manuals, Swanson Analysis Systems, Inc., 1991. Edition, 1987 . 13. Properties and Selection: Nonferrous Alloys and Special-Purpose Materials, Materials Handbook, ASM, 10th Edition, 2, 1990.

14. J.G. Sanfeliz, NASA TM 106304, 1993.

15. P.J. Rudnik, A.D. Krawitz, D.G. Reichel, and J.8. Cohen, Adv. X-Ray Anal., 31
245, 1987.

\section{DISCLAIMER}

This report was prepared as an account of work sponsored by an agency of the United States Government. Neither the United States Government nor any agency thereof, nor any of their employees, makes any warranty, express or implied, or assumes any legal liability or responsibility for the accuracy, completeness, or usefulness of any information, apparatus, product, or process disclosed, or represents that its use would not infringe privately owned rights. Reference herein to any specific commercial product, process, or service by trade name, trademark, ence herein to an serwise does not necessarily constitute or imply its endorsement, recommanufacturer, or otherwise doe United States Government or any agency thereof. The views mendation, or faver authors expressed herein do not necessarily state or reflect those of the United States Government or any agency thereof. 